\title{
ANALISIS KUALITAS JALUR DISTRIBUSI MENGGUNAKAN ETAP POWER STATION 12.6.0 PADA GARDU POLITEKNIK PENERBANGAN INDONESIA
}

\author{
${ }^{1}$ HENDRO WIDIARTO, ${ }^{2}$ YAYUK SUPRIHARTINI \\ 1,2, Politeknik Penerbangan Indonesia Curug, Tangerang. \\ Email: hendro.widiarto@ppicurug.ac.id, yayuk.suprihartini@ppicurug.ac.id
}

\begin{abstract}
ABSTRAK
Sistem distribusi yaitu sistem penyalur tenaga listrik dari sumber daya listrik utama/Induk sampai dengan ke konsumen. Politeknik Penerbangan Indonesia curug mempunyai sumber listrik utama yaitu Gardu induk LGK 35 yang mencakup kebutuhan listrik pada gedung hangar satu teknik pesawat udara, gedung keselamatan penerbangan, gedung PKP-PK, dan warehouse yang memerlukan distribusi jaringan listrik dengan kehandalan yang baik sebagai pendukung kegiatan pembelajaran taruna taruni Politeknik Penerbangan Indonesia curug. Jalur distribusi yang handal memiliki beberapa kriteria yaitu, keandalan kontinuitas dan kecukupan yang harus dipenuhi secara optimal. Untuk memenuhi kehandalan sistem jaringan distribusi listrik maka diperlukan sistem keamanan proteksi yang bertingkat dengan menggunakan software ETAP Power Station 12.6.0 untuk penghitungan sumber listrik dari gardu induk sampai dengan konsumen. Dengan menggunakan software ETAP diharapkan dapat mengetahui nilai aliran daya dan rugi-rugi daya yang mengalir pada sistem tenaga listrik di Politeknik Penerbangan Indonesia curug sehingga apabila ada gangguan di salah satu jaringan distribusi listrik tidak mempengaruhi jaringan distribusi listrik yang lain.
\end{abstract}

Kata kunci : Analisis, Jalur Distribusi Listrik, ETAP Power Station 12.6.0.

\section{ABSTRACT}

The distribution system is a system of distributing electricity from the main /main power source to the consumer. The Indonesian Aviation Polytechnic Curug has a main power source, namely the LGK 35 substation which includes the electricity needs of the aircraft engineering hangar building, aviation safety building, PKP-PK building, and warehouses that require distribution of electricity networks with good reliability to support cadet learning activities. Indonesian Aviation Polytechnic student curug. A reliable distribution channel has several criteria, namely, reliability, continuity and adequacy that must be fulfilled optimally. To meet the reliability of the electricity distribution network system, a cascading protection security system is needed using the ETAP Power Station 12.6.0 software for calculating the power source from the substation to the consumer. By using ETAP software, it is expected to be able to find out the value of power flow and power losses flowing in the electric power system at the Indonesian Aviation Polytechnic waterfall so that if there is a disturbance in one electricity distribution network it does not affect other electricity distribution networks.

Keyword : Electrical Distribution Line, ETAP Power Station 12.6.0.

\section{PENDAHULUAN}

Menurut Suhadi, dkk (2008), Sistem distribusi merupakan bagian dari sistem tenaga listrik. Sistem distribusi ini berguna untuk menyalurkan tenaga listrik dari pembangkit sampai ke konsumen. Tenaga listrik yang dihasilkan oleh pembangkit tenaga listrik besar dengan tegangan dari $11 \mathrm{kV}$ sampai $24 \mathrm{kV}$ dinaikan tegangannya oleh gardu induk dengan transformator penaik tegangan menjadi $70 \mathrm{kV}, 150 \mathrm{kV}, 220 \mathrm{kV}$ atau $500 \mathrm{kV}$ kemudian disalurkan melalui saluran transmisi.

Dari saluran transmisi, tegangan diturunkan lagi menjadi $20 \mathrm{kV}$ dengan transformator penurun tegangan pada gardu induk distribusi, kemudian dengan sistem tegangan tersebut penyaluran tenaga listrik dilakukan oleh saluran distribusi primer. Dari saluran distribusi primer inilah gardu-gardu distribusi mengambil tegangan untuk diturunkan tegangannya dengan trafo distribusi menjadi sistem tegangan rendah, yaitu 220/380Volt. Selanjutnya disalurkan oleh 
saluran distribusi sekunder ke konsumen-konsumen. Dengan 7 ini jelas bahwa sistem distribusi merupakan bagian yang penting dalam sistem tenaga listrik secara keseluruhan. Suhadi, dkk (2008).

Gardu distribusi adalah komponen penting dalam penyaluran pada sistem distribusi tenaga listrik yang berfungsi untuk menurunkan tegangan dari tegangan menengah ke tegangan rendah untuk disalurkan dan digunakan oleh pelanggan. Di dalam gardu distribusi terdapat beberapa peralatan listrik seperti panel hubung bagi Tegangan Menengah, panel hubung bagi Tegangan Rendah, dan transformator distribusi 20 kV/ 380 V (Rasimun, 2012).

Pada lampiran Peraturan Menteri Energi Dan Sumber Daya Mineral Nomor : 04 Tahun 2009 Tanggal 20 Februari 2009 Tentang Aturan Distribusi Tenaga Listrik perencanaan sistem distribusi yang dilakukan untuk menjamin keamanan, mutu dan keandalan system distribusi, yaitu dengan mengaji drop tegangan, hubung singkat, ssut distribusi dan keandalan distribusi sehingga kontinyuitas pada perancangan jalur distribusioptimal.

Gardu LGK 35 PPI Curug sebagai sumber yang mencakup kebutuhan listrik pada gedung hangar $1 \mathrm{TPU}$, gedung keselamatan penerbangan, gedung PKP-PK, dan ware house memerlukan dukungan listrik dengan keandalan yang baik sebagai pendukung kegiatan pembelajaran taruna karena terdapat peralatan sebagai sarana pembelajaran untuk memenuhi syarat kualifikasi pendidikan dan sebagai pendukung kegiatan yang melibatkan instansi lain dalam penggunaan fasilitas yang tersedia pada jalur distribusi tersebutPada saat ini teknisi hanya mengatahui ada salah satu fasa yang hilang dalam sistem 3 fasa, akan tetapi tidak megetahui fasa manakah yang hilang apakah itu fasa $\mathrm{R}, \mathrm{S}$ atau $\mathrm{T}$.

Peralatan yang di maksud diantaranya simulator dan peralatan praktikum yang sangat penting sebagai penunjang pembelajaran pada Program Studi PPI Curug. Peralatan terebut digunakan dengan waktu operasi yang cukup lama, yaitu selama jam pendidikan berlangsung. Sehingga kontinyuitas jalur distribusi pada gardu LGK35 sangat penting dan berpengaruh terhadap hasil pembelajaran jurusan keselamatan penerbangan dan teknik penerbangan PPI Curug. Maka dari itu sangat diperlukan dukungan listrik dengan kualitas dan keandalan yang baik pada jalur distribusi gardu LGK 35 sehingga bisa dilakukan pencegahan apabila terdapat hal yang dapat mengganggu keandalan pada jalur distribusi gardu LGK 35.

Penelitian ini bertujuan untuk mengetahui voltage drop pada jalur distribusi dan mendapatkan hasil analisis keandalan jalur distribusi pada gardu LGK 35 PPI Curug dengan menggunakan etap power station sehingga hasil data yang diperoleh di gunakan untuk menganalisis kontinyuitas jalur distribusi listrik dengan pengamatan pada SLD jalur distribusi.

\section{METODE PENELITIAN}

Kontinyuitas jalur distribusi pada gardu LGK 35 sangat penting dan berpengaruh terhadap hasil pembelajaran jurusan keselamatan penerbangan dan teknik penerbangan PPI Curug. Maka dari itu sangat diperlukan dukungan listrik dengan kualitas dan keandalan yang baik pada jalur distribusi gardu LGK 35 sehingga bisa dilakukan pencegahan apabila terdapat hal yang dapat mengganggu keandalan pada jalur distribusi gardu LGK 35.

Penelitian Analisis Kualitas Jalur Distribusi Menggunakan Etap Power Station 12.6.0 di laksanakan pada bulan Juni 2021 untuk mengambil data, mengolah data, dan menganalisa data yang berlokasi di Gardu LGK 35 Politeknik Penerbangan Indonesia Curug. Adapun metode penelitian yang di gunakan adalah Studi Literature dengan mencari referensi berupa teori-teori kelistrikan khususnya mengenai sistem distribusi listrik dan menggunakan referinsi jurnal ilmiah sebelum sebagai salah satu ajuan di dalam penelitian. Setelah studi literature di peroleh Langkah selanjutnya peneliti melakukan metode eksperimen dengan menggunakan program Etap Power Station 12.6.0.

Dalam pelaksanaan penelitian ini, penulis menentukan waktu yang dilakukan untuk mengambil data, mengolah data, dan menganalisa data yang berlokasi di Gardu LGK 35 PPI Curug sampai penulis menyusun penelitian ini berupa laporan Tugas Akhir yang dimulai dari Januari 2021 sampai dengan Agustus 2021. 


\begin{tabular}{|c|c|c|c|c|c|c|c|c|c|c|}
\hline \multirow{2}{*}{ No. } & \multirow{2}{*}{ Kegiatan } & \multicolumn{9}{|c|}{ Bulan ke- } \\
\hline & & 1 & 2 & 3 & 4 & 5 & 6 & 7 & 8 & 9 \\
\hline \multirow{3}{*}{1} & Identifikasi Masalah & & & & & & & & & \\
\hline & Perencanaan Judul & & & & & & & & & \\
\hline & Pengajuan Judul Tugas Akhir & & & & & & & & & \\
\hline \multirow[b]{2}{*}{2} & Penulisan Proposal Tugas Akhir & & & & & & & & & \\
\hline & $\begin{array}{l}\text { Pengumpulan Data dan Teori } \\
\text { Pendukung }\end{array}$ & & & & & & & & & \\
\hline 3 & Sidang Proposal Tugas Akhir & & & & & & & & & \\
\hline \multirow{2}{*}{4} & Penulisan Tugas Akhir & & & & & & & & & \\
\hline & Pengerjaan Tugas Akhir & & & & & & & & & \\
\hline 5 & Pengajuan Sidang Tugas Akhir & & & & & & & & & \\
\hline 6 & Sidang Tugas Akhir & & & & & & & & & \\
\hline 7 & Revisi Tugas Akhir & & & & & & & & & \\
\hline
\end{tabular}

Adapun teknik pengumpulan data yang dilakukan dalam penelitian ini sebagai berikut:

1. Observasi

Observasi dilakukan di Gardu LGK 35 PPI Curug. Dalam observasi ini diperoleh berupa data transformator, data bus, data sistem pengaman, dan data beban di Gardu LGK 35 PPI Curug.

2. Studi Literature

Studi literature dilakukan dengan mencari referensi dari buku, jurnal ilmiah dan sumbersumber bacaan elektronik yang sesuai dengan permasalahan yang akan peneliti lakukan.

3. Metode Wawancara

Wawancara dilakukan dengan teknisi unit listrik di Politeknik Penerbangan Indonesia Curug untuk pengumpulan data dan informasi terkait jalur distribusi Gardu LGK 35 PPI Curug karena belum adanya data konkrit seperti hardfile ataupun softfile terkait keadaan eksisting pada jalur distribusi gardu LGK 35 PPI Curug.

Data yang digunakan yaitu data sekunder seperti spesifikasi peralatan dan gambar peralatan yang diambil penulis dengan observasi gardu LGK 35 PPIC dan juga data yang penulis peroleh dari teknisi listrik di Politeknik Penerbangan Indonesia Curug atau sumber lainnya.

Setelah Teknik pengumpulan data dilakukan langkah selanjutnya adalah peneliti akan melaksanakan penelitian dengan melakukan analisis dan pembahas data-data yang di dapat dari hasil penelitian kemudian akan ditarik kesimpulan berdasaran dari referensi teori dan jurnal yang di gunakan sebagai acuan. 


\section{HASIL DAN PEMBAHASAN}

\section{Hasil}

a. Single Line Diagram

Jalur distribusi pada gardu LGK 35 PPI Curug disuplai melalui feeder PLN yang berkapasitas 1.040kVa dengan tegangan $20 \mathrm{kV}$. Berikut Single Line Diagram jalur distribusi listrik pada gardu LGK 35 PPI Curug. Penyaluran distribusi dari PLN melalui jalur bawah tanah terhubung ke main incoming cubicle pada gardu LGK 35 yang terletak di samping gedung Hanggar 01 PPI Curug. Dari cubicle main incoming PLN keluar menuju trafo stepdown dengan kapsitas $1000 \mathrm{kVA}$ yang menurunkan tegangan menengah $20 \mathrm{kV}$ menjadi tegangan rendah 220/380 V. tegangan yang sudah di turunkan masuk ke LVMDP untuk di distribusikan ke beban yang mencakup gedung Hanggar 01 TPU, gedung Keselamatan Penerbangan, gedung PKPPK dan Ware house.

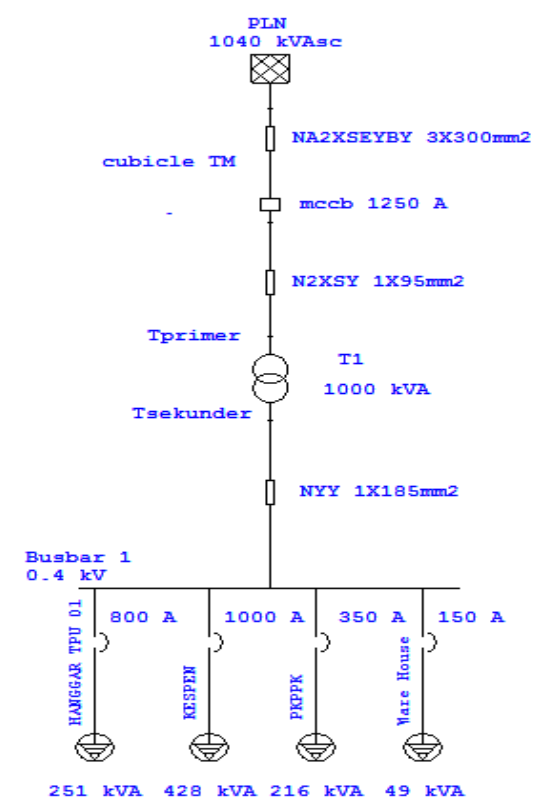

\section{Gambar 2. Single Line Diagram Jalur Distribusi Gardu LGK 35 PPI Curug}

b. Kecukupan Catu Daya PLN

Untuk menganalisis kecukupancatu daya listrik dari PLN maka dibutuhkan penghitungan daya nyata, daya reaktif, dan daya semu pada jalur distribusi. Daya nyata, daya reaktif dan daya semu digunakan untuk mengetahui kebutuhan daya yang terpakai. Daya tersebut yang nantinya akan dianalisis apakah sudah tercukupi dengan catu daya yang tersedia. Berikut tabel data hasil penghitungan load flow analysis untuk catu daya PLN sesuai dengan SLD catu daya PLN. 
Tabel 1. Hasil Perhitungan Load Flow Analysis Catu Daya PLN

\begin{tabular}{|l|l|l|l|}
\hline Aliran daya & $\begin{array}{l}\text { Daya semu } \\
(\mathrm{S}=\mathrm{kVA})\end{array}$ & $\begin{array}{l}\text { Daya nyata } \\
(\mathrm{P}=\mathrm{kW})\end{array}$ & $\begin{array}{l}\text { Daya realtif } \\
(\mathrm{Q}=\mathrm{kvar})\end{array}$ \\
\hline $\begin{array}{l}\text { PLN menuju } \\
\text { trafo }\end{array}$ & 906 & 710 & 564 \\
\hline $\begin{array}{l}\text { Trafo menuju } \\
\text { LVMDP }\end{array}$ & 853 & 682 & 512 \\
\hline $\begin{array}{l}\text { LVMDP } \\
\text { menuju } \\
\text { gedung } \\
\text { Hanggar } 01 \\
\text { TPU }\end{array}$ & 226 & 181 & 136 \\
\hline $\begin{array}{l}\text { LVMDP } \\
\text { menuju gedung } \\
\text { KESPEN }\end{array}$ & 387 & 309 & 232 \\
\hline $\begin{array}{l}\text { LVMDP } \\
\text { menuju } \\
\text { gedung } \\
\text { PKPPK }\end{array}$ & 195 & 156 & 117 \\
\hline $\begin{array}{l}\text { LVMDP menuju } \\
\text { Ware House }\end{array}$ & 44 & 35 & 26 \\
\hline
\end{tabular}

Dapat dilihat pada Tabel Busbar Main Incoming PLN memiliki daya nyata, daya reaktif dan saya semu paling besar yaitu 710kW, 564 kVAR, dan $906 \mathrm{kVA}$. Jika dibandingkan dengan catu daya PLN yang tersedia, beban $906 \mathrm{kVA}$ yaitu 87,11 \% dari kapasitas catu daya PLN yaitu 1040kVA. Dan juga tidak menunjukan adanya indikasi pada alert view. Apabila dihitung manual dengan rumus segitiga daya pada daya aktif,daya reaktif dan daya semu, maka akan mendapatkan hasil sebagai berikut:

Tabel 2. Hasil Perhitungan Manual Beban

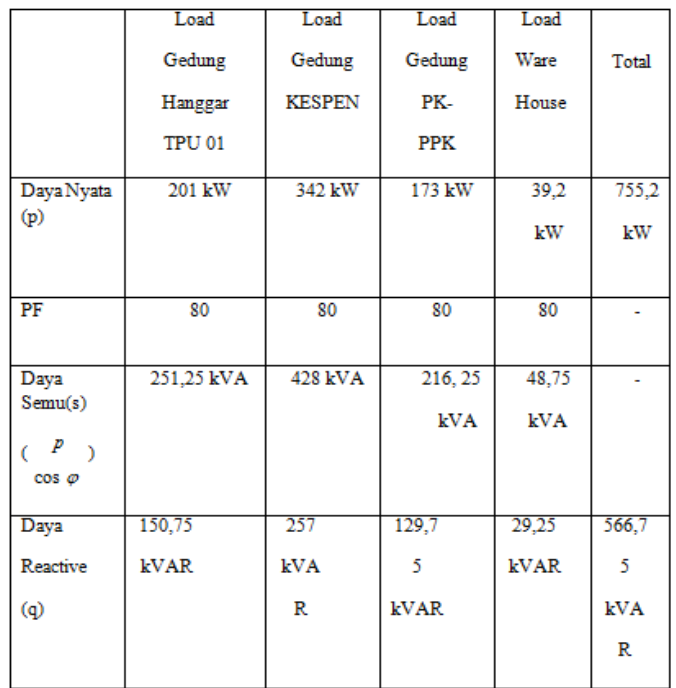

Dari tabel diatas dapat ditentukan total daya semu pada beban, yaitu:

$\mathrm{S}=\sqrt{P^{2}+Q^{2}}$

$\mathrm{S}=\sqrt{755,2^{2}+566,75^{2}}$

$\mathrm{S}=944,2 \mathrm{kVA}$

Total beban pada jalur distribusi Gardu LGK 3 PPI Curug yaitu 944,2 kVA yang dalam persentase adalah 90,7\% dari kapasitas PLN yang tersedia. Sehingga dapat disimpulkan bahwa beban dan peralatan listrik yang terpasang masih tercukupi catu daya listrik dari PLN dengan kapasitas yang tersedia yaitu $1040 \mathrm{kVA}$. 


\section{Pembahasan}

\section{Sistem Tenaga Listrik}

Dalam penelitian ini menggunakan beberapa Teori kelistrikan sebagai berikut :

Sebuah sistem tenaga listrik adalah sebuah jaringan terinterkoneksi yang berfungsi untuk mendistribusikan listrikdari pembangkit ke pengguna. Sistem tenaga listrik terdiriatas :

a. Pembangkit TenagaListrik

Pusat pembangkitan yang menggunakan energi potensi mekanik (air, uap, panas bumi, nuklir dll) untuk menggerakan turbin yang porosnya dikopel atau digandeng dengan generator. Dari generator yang berputar menghasilkan energi listrik. Energi listrik yang dihasilkan disalurkan ke gardu induk melalui jaringan transmisi, kemudian langsung di distribusikan ke konsumen melalui jaringandistribusi.

b. Gardu Listrik

Gardu listrik adalah sebuah bagian dari sistem pembangkit, transmisi dan distribusi listrik. Gardu listrik mengubah tegangan listrik dari tinggi menjadi rendah, atau sebaliknya

c. Saluran TransmisiListrik

Transmisi tenaga listrik adalah proses penghantaran tenaga listrik secara besar-besaran dari pembangkit listrik, ke gardu listrik.

d. Saluran Distribusi

Sistem Distribusi merupakan bagian dari sistem tenaga listrik. Sistem distribusi ini berguna untuk menyalurkan tenaga listrik dari sumber daya listrik besar (Bulk Power Source) sampai ke konsumen.

\section{Aliran daya}

Dalam persamaan maupun perhitungan daya, hal pokok yang harus dipahami adalah dengan memahami konsep segitiga daya. Berikut ini akan dijelaskan tentang segitiga daya menggunakan gambar disertai penjelasan dan perhitungannya (Dhimas, 2014:17). Dalam sistem tenaga listrik dikenal tiga jenis daya, yaitu daya aktif atau real power $(\mathrm{P})$, daya reaktif atau reactive power $(\mathrm{Q})$, dan daya nyata atau apparent power $(\mathrm{S})$. Daya aktif $(\mathrm{P})$ adalah daya listrik yang dibangkitkan di sisi keluaran generator, kemudian termanfaatkan oleh konsumen, dapat dikonversi ke bentuk energi lainnya seperti energi gerak pada motor, bisa juga menjadi energi panas pada heater ataupun dapat diubah kebentuk energi listrik lainnya. Perlu diingat bahwa daya ini memiliki satuan watt $(\mathrm{W})$, kilowatt $(\mathrm{kW})$ atau tenaga kuda $(\mathrm{HP})$ (Sigit, 2015 : hal.19).

Sedangkan daya reaktif (Q) adalah suatu besaran yang digunakan untuk menggambarkan adanya fluktuasi daya pada saluran transmisi dan distribusi akibat dibangkitkannya medan/daya magnetik atau beban yang bersifat induktif (seperti : motor listrik, trafo, dan las listrik).Walaupun namanya adalah daya, namun daya reaktif ini tidak nyata dan tidak bisa dimanfaatkan. Daya ini memiliki satuan volt-ampere-reaktif (VAR) atau kilovar (kVAR). Daya semu (S) merupakan jumlah daya total yang terdiri dari daya aktif (P) dan daya reaktif (Q).

\section{ETAP Power Station}

ETAP atau Electric Transient and Analysis Program merupakan suatu perangkat lunak yang mendukung sistem tenaga listrik. Perangkat ini mampu bekerja dalam keadaan offline untuk simulasi tenaga listrik, online untuk pengelolaan data real-time atau digunakan untuk mengendalikan sistem secara real-time. Fituryang terdapat di dalamnya pun bermacam-macam antara lain fitur yang digunakan untuk menganalisa pembangkitan tenaga listrik, sistem transmisi maupun sistem distribusi tenaga listrik.ETAP ini awalnya dibuat dan dikembangkan untuk meningkatkan kualitas keamanan fasiitas nuklir di Arnerika Serikat yang selanjutnya dikembangkan menjadi sistem monitor manajemen energi secara real time, simulasi, kontrol, dan optimasi sistem tenaga listrik.(Awaluddin,2007). 


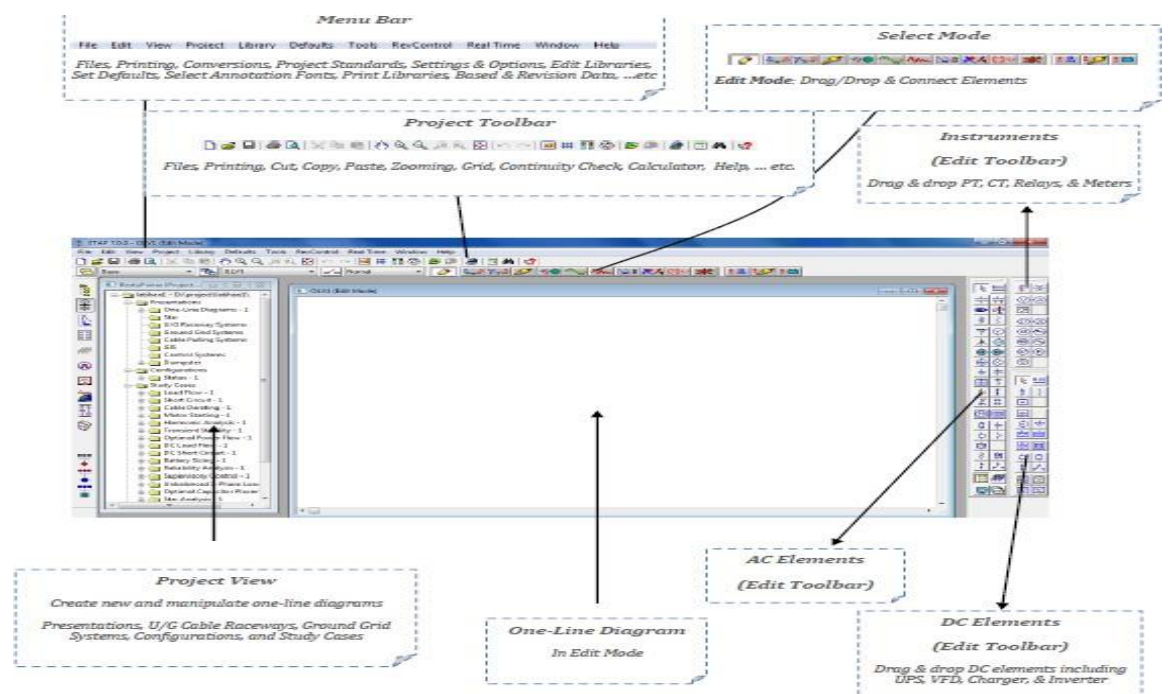

Gambar 1. Tampilan ETAP Power Station

ETAP yang di guanakan penilis yaitu ETAP Power Station 12.6.0. ETAP mampu bekerja dalam keadaan offline untuk simulasi tenaga listrik, dan online untuk pengelolaan data real-time atau digunakan untuk mengendalikan sistem secara real-time. Fitur yang terdapat di dalamnya pun bermacam-macam antara lain fitur yang digunakan untuk menganalisa pembangkitan tenaga listrik, sistem transmisi maupun sistem distribusi tenaga listrik. Analisa sistem tenaga listrik yang dapat dilakukan ETAP antara lain:

- Analisa alirandaya

- Analisa hubungsingkat

- Arc Flash Analysis

- Startingmotor

- Koordinasiproteksi

- Analisa kestabilan transien

Menurut Rahman Adam pada tahun 2018, menyatakan bahwa kriteria yang harus dipenuhi untuk mencapai jalur distribusi dengan kualitas yang optimal, yaitu:

a. Kecukupan (adequacy)

Agar pasokan listrik ke bandara bisa memenuhi kebutuhan beban yang tersedia ketika pasokan lebih rendah maka akan terdapat peralatan yang tidak dapat dioperasikan akibat tidak adanya pasokan listrik, begitu juga sebaliknya.

b. Keandalan (reliability)

Pasokan listrik yang mengalir ke bandara harus terjaga keandalannya, karena listrik tidak boleh padam, apabila listrik padam maka harus segera ada yang memback-up pasokan listrik lain dengan jangka waktu yang sesingkat mungkin (Adam,2018).

Berdasarkan tinjauan teori penulis kan membahasn hasil penelitian yang diperoleh sebagai berikut :

a. Keandalan Jalur Distribusi

Untuk menganalisis keandalan pada jalur distribusi dibutuhkan penghitungan tegangan pada busbar dan hasil alert view pada fitur ETAP Power Station 12.6.0 juga pengamatan Single Line Diagram sistem distribusi agar dapat mengetahui apakah terdapat kelemahan dalam sistem distribusi. Hasil penghitungan tegangan pada busbar yang penulis lakukan dalam software ETAP Power Station. Berikut hasil simulasi load flow analysis untuk besar tegangan pada busbar pada saat di supply oleh catu daya PLN. 
Vol 2. No. 1, Januari 2022 P-ISSN : 2774-8030, e-ISSN : 2774-8030

Tabel 3. Hasil Persentase Tegangan pada Busbar Catu Daya PLN

\begin{tabular}{|l|c|c|c|}
\hline Nama busbar & $\begin{array}{c}\text { Presentase } \\
\text { Tegangan }\end{array}$ & $\begin{array}{c}\text { Tegangan } \\
\text { Pada Busbart }\end{array}$ & Keterangan \\
\hline Cubicle TM & $100 \%$ & $20 \mathrm{kV}$ & bailk \\
\hline Primer Trafo & $99,99 \%$ & $20 \mathrm{kV}$ & bailk \\
\hline Sekunder Trafo & $94,08 \%$ & $0,37 \mathrm{kV}$ & bailk \\
\hline Busbar 1 & $94,08 \%$ & $0,37 \mathrm{kV}$ & bailk \\
\hline
\end{tabular}

Besar tegangan yang baik pada busbar adalah besar tegangan yang sesuai dengan spesifikasi tegangan menengah yang diinginkan yaitu $20 \mathrm{kV}$. Besar tegangan dikatakan kurang baik apabila persentase pada busbar dibawah $90 \%$ atau melebihi $105 \%$ sesuai dengan Standar PLN.

Voltage drop adalah jatuh tegangan merupakan besarnya tegangan yang hilang pada suatu penghantar. Jatuh tegangan pada saluran tenaga listrik secara umum berbanding lurus dengan panjang saluran dan beban serta berbanding terbalik dengan luas penampang penghantar. Besarnya jatuh tegangan dinyatakan baik dalam persen atau dalam besaran Volt. Besarnya batas atas dan bawah ditentukan oleh kebijaksanaan perusahaan kelistrikan. Perhitungan jatuh tegangan praktis pada batas-batas tertentu dengan hanya menghitung besarnya tahanan masih dapat dipertimbangkan, namun pada sistem jaringan khususnya pada sistem tegangan menengah masalah indukstansi dan kapasitansinya diperhitungkan karena nilainya cukup berarti (PT.PLN (Persero),2010: hal20).

Tegangan jatuh secara umum adalah tegangan yang digunakan pada beban. Tegangan jatuh ditimbulkan oleh arus yang mengalir melalui tahanan kawat. Tegangan jatuh $\mathrm{V}$ pada penghantar semakin besar jika arus I di dalam penghantar semakin besar dan jika tahanan penghantar $\mathrm{R} \ell$ semakin besar pula. Tegangan jatuh merupakan penanggung jawab terjadinya kerugian pada penghantar karena dapat menurunkan tegangan pada beban. Akibatnya hingga berada di bawah tegangan nominal yang dibutuhkan. Atas dasar hal tersebut maka tegangan jatuh yang diijinkan untuk instalasi arus kuat hingga $1.000 \mathrm{~V}$ yang ditetapkan dalam persen dari tegangan kerjanya (Daryanto,2010: hal 18 \& 42).

Terdapat beberapa aturan sebagai standart kualitas yang baik, diataranya; SPLN 1:1978 Pasal 4 Variasi Tegangan Pelayanan merupakan perubahan nilai tegangan pelayanan pada kerja normal terhadap tegangan nominal yang disebabkan oleh perubahan beban (tidak termasuk gejala transien dan abnormal) dan usaha pengaturan tegangan. Sedangkan ketentuan variasi tegangan pelayanan ditetapkan maksimum $+5 \%$ minimum $-10 \%$ terhadap tegangan nominal.

Pada hasil tabel diatas dapat disimpulkan bahwa range tegangan pada jalur distribusi gardu LGK 35 PPI Curug dalam keadan baik karena besar tegangan tidak dibawah $90 \%$ atau melebihi $105 \%$ sesuai dengan Standar tegangan yang di tentukan oleh PLN. Sedangkan penelitian sebelumnya minimum yang dihasilkan algoritma MST dapat mempengaruhi penurunan tegangan pada jaringan listrik distribusi primer rata-rata sebesar 10,062 \% dari tegangan sumber (Hardianto, 2015).

b. Kontinuitas Jalur Distribusi

Dari hasil pengamatan jalur distribusi pada SLD gardu LGK 35 PPI Curug menunjukan adanya kelemahan terkait kontinyuitas pada jalur tersebut yaitu kurangnya sumber catu daya cadangan pada jalur distribusi listrik menuju gedung Keselamatan Penerbangan. Pada jalur distribusi listrik di gardu LGK 35 PPI Curug, hanya terdapat dua buah Generator dengan 
kapasitas 500 kVA untuk mem-backup sebagian beban pada gedung Hanggar 01 TPU dan 250kVA untuk mem-backup beban pada gedung PKPPK. Sedangkan jalur distribusi listrik LGK 35 PPI Curug mencakup gedung Hanggar 01 TPU, gedung Keselamatan Penerbangan, Gedung PKPPK dan Ware House yang mayoritas adalah sarana pendidikan yang sangat berperan penting dalam pelaksanaan pembelajaran taruna. Sehingga jika catu daya PLN tidak beroperasi maka gedung yang tidak memiliki catu daya cadangan sehingga tidak dapat beroperasi dan menghambat proses pembelajaran seperti praktikum yang rutin dilakukan.

\section{KESIMPULAN}

Berdasarkan hasil penelitian dapat diambil kesimpulan bahwa hasil analisis aliran daya pada jalur distribusi gardu LGK 35 PPI Curug dalam perhitungan mengunakan ETAP Power Station 12.6.0 nilai penggunaan beban terpasang yaitu 87,11 \% dari kapasitas catu daya PLN yaitu $1040 \mathrm{kVA}$, sedangkan perhitungan manual nilai penggunaan beban terpasang yaitu 90,7\% dari kapasitas PLN yaitu 1040kVA. Dari hasil perhitungan tersebut tidak memiliki selisih yang besar, maka hasil tersebut jelas menunjukan bahwa catu daya PLN saat ini masih dapat mencukupi kebutuhan beban. Hasil analisis tegangan pada busbar jalur distribusi gardu LGK 35 PPI Curug turunnya perentase tegangan paling besar berada pada busbar 1 dengan 94,08 \% dari tegangan nominal $0,4 \mathrm{kV}$. Persentase tegangan tersebut masih dalam keadan baik karena besar tegangan tidak dibawah 90\% atau melebihi 105\% sesuai dengan Standar PLN 1 : 1978.

Kontinyuitas jalur distribusi gardu LGK 35 PPI Curug berdasarkan hasil pengamatan jalur distribusi pada Single Line Diagram gardu LGK 35 PPI Curug menunjukan adanya kelemahan dengan tidak ada nya catu daya cadangan untuk mem-backup catu daya utama pada jalur distribusi menuju gedung Keselamatan Penerbangan. Sehingga jika catu daya utama tidak beroperasi maka beban pada gedung yang tidak memiliki catu daya cadangan tidak dapat beroperasi.

\section{DAFTAR PUSTAKA}

Abdillah, Anif. (2019) Rancang Bangun Alat Proteksi Pemindahan Dari Catu Daya Utama (PLN) ke Catu Cadangan (Genset) Secara Otomatis Berbasis Arduino Mega. Kumpulan Karya Ilmiah Mahasiswa Fakultas sains dan Tekhnologi Vol. 1 No. 1.

H Hardianto. (2015). Penentuan Penurunan Tegangan Berdasarkan Minimum Spanning Tree Pada Jaringan Listrik Distribusi Primer. Jurnal Teknik Elektro Vol. 15 No. 01.

Jhonson M. Siburian, Thamrin Siahaan \& Johannes Sinaga. (2020). Analisis Peningkatan Kinerja Jaringan Distribusi 20KV Dengan Metode Thermovisi Jaringan PT. PLN (Persero) Ulp Medan Baru. Jurnal Teknologi Energi Uda Volume 9, Nomor 1, 8-19

Kadir, A. (2017). Distribusi Tenaga Listrik

Lesnanto, M. \& Aridani, R. P. (2013). Modul Pelatihan ETAP. In Jurusan Teknik Eektro dan Teknologi Informasi; Uniiversitas Gadjah Mada.

Muhammadiyah, U. (2019) Buku Panduan Praktikum Analisis Sistem Tenaga.

Nigara. (2015). Analisis Aliran Daya Sistem Tenaga Listrik Pada Bagian Texturizing Di PT Asia Pasific Fibers Tbk Kendal Menggunakan Software Etap Power Station 4.0., Universitas Negeri Semarang.

Pandapotan, S. (2014). Penggunaan ETAP 12.6 Sebagai Software Analisis Power Quality. 123 127

S., Arief, J., \& Hakim, R. (n.d.). (2016). MONITORING KUALITAS DAYA OUTPUT TRAFO DISTRIBUSI BERBASIS MIKROKONTROLER VIA WIFI Dika Mahendra Anggiyatna , Ikhlasul Amal, Ir . Josaphat Pramudijanto , M . Eng . 1-6.

Sekretariat Departemen Energi dan Sumber Daya Mineral. UU Nomor 4 Tahun 2009 Tentang Aturan Distribusi Tenaga Listrik. 8. Jakarta.

Suhadi, \& Wrahatnolo, T. (2012). Teknik Distribusi Tenaga Listrik. In Journal of Chemical Information and Modeling (Vol. 53, Issue 9). 